\title{
ETHNOBOTANICAL AND ANTIMICROBIAL STUDIES OF SOME PLANTS USED IN KIBWEZI (KENYA) FOR MANAGEMENT OF LOWER RESPIRATORY TRACT INFECTIONS
}

\author{
Kariuki A. C. and Njoroge, G. N. \\ Jomo Kenyatta University of Agriculture and Technology \\ Botany Department; P.O. Box 62000, Nairobi \\ E-mail: gnjerinjoroge@hotmail.com, gnjoroge@fsc.jkuat.ac.ke
}

\begin{abstract}
Respiratory tract infections have gained worldwide recognition especially due to the increased incidence of HIV/AIDS. The bacteria responsible for these infections have also become increasingly resistant to chemotherapeutic agents in lower respiratory infections in Kibwezi in Kenya. Interviews were conducted using semi-structured questionnaires and detailed discussions with respondents. During the field surveys direct observations were made on how these plants are used. From the ethnobotanical survey the modes of preparation used included chewing and boiling. The plant parts used were mostly bark and root, which implies that the main methods of harvesting these plants are destructive in nature. Water and methanolic extracts of the three most popular plants, Acacia nilotica, Strychnos heninngsii and Microglossa densiflora were tested against three test organism: Staphylococcus aureus, Streptococcus pneumoniae and Escherichia coli for their antimicrobial properties. The efficacy of the extracts was tested by bioassay method using the disk diffusion test. It was interesting to note that none of the tested water extracts showed any activity against the test organisms. This is despite the fact that about $83 \%$ of the local people used water for extraction. Methanolic extracts of Acacia nilotica and Strychnos heninningsii showed efficacy against $S$. aureus, $S$. pneumoniae and E. coli. The findings of this research indicate that A. nilotica and S. heninngsii have antimicrobial properties and further work especially using mammalian models is recommended.
\end{abstract}

Key words: Medicinal plants, lower respiratory infections, antimicrobial growth inhibitory potential

\section{Introduction}

Plants have been described as the oldest friends of man due to their value as sources of food, shelter and medicines (Akerele et al., 1990; Gilan and Rahman, 2005; Rios and Rico, 2005). Estimates show that by the nineteenth century $80 \%$ of all medicines originated from plants (Gilan and Rahman, 2005). The World Health Organization (WHO) has estimated that $80 \%$ of the global population in developing countries depends on traditional medicines mainly from plants (WHO, 2002). In developing countries there is an increasing attempt to incorporate traditional medicines in local health care systems. Several countries in Africa have realized the need to develop improved traditional medicines (ITMs) from local plants that are used traditionally for various ailments (Inngjerdingen et al., 2004). This calls for systematic study of local plants utilization in managing primary healthcare and antimicrobial trials to authenticate the use of such medicines in various communities. Approximately $25 \%$ of all pharmaceutical products worldwide originated from traditional medicinal knowledge. There is widespread interest in developing new types of medicinal agents with greater potency and reduced side effects. Higher success rates have been reported when indigenous knowledge is integrated in the process on bioprospecting activities than using random screening (Carlson, et al., 1997; Fauci, 1998).

There are many drugs in clinical use today that were discovered from the way plants were used in traditional communities. Such discoveries include quinine which has been used to manage malaria for many years (van Wyk et al., 2002), Digitoxin used for heart conditions, Taxol which is used as modern therapy for ovarian cancer (Farnsworth, 1990; Iwu, 1993). So far two thirds of the global medicinal plants are known to grow in tropical countries (Gasengayire, 2003) and only less than 90 species have been well investigated of their potential.

Traditional medicine is currently the fastest growing medical field with herbal therapies becoming increasingly popular. This mode of treatment is preferred because it is considered more holistic, acceptable, accessible, low cost and proven to be safe (Gessler, 1995). Globally, there is an increase in the number of countries regulating the sale of botanical drugs (ethnoherbals) with current value estimated at US\$ 60 billion per annum (Barnes et al., 2002). This global increase in demand for ethnoherbals is also attributed to dissatisfaction with conventional medicine in terms of effectiveness and/or safety. Further, there is continued search for novel products from traditional medicinal plants (Makunga et al. 2008) particularly for development of effective new drugs that are non-toxic and inexpensive (Taylor et al., 2001).

It has been reported that in Kenya for example, about $90 \%$ of the population has consented to have used traditional medicines at least once for various health conditions (Chirchir et al. 2006). In Kenya, the number of patients being treated in traditional health facilities is on the increase, sometimes reaching well over 500 patients per month attended to by just one 
Kariuki and Njoroge Afr J Tradit Complement Altern Med. (2011) 8(2):144-149

herbalist (Njoroge, 2006). The Karati Rural Service Center for example, reported an increase in the number of patients from 805 in 1985 to 3726 in 1990 (Githae, 1995). The unresolved question is whether these therapies are effective or not against known microorganisms. Some studies on some of the East African medicinal plants show that they have activity against known microorganisms (Okemo, 1996; Fabry et al., 1998).

The knowledge of medicinal plants that may contain bioactive agents lies with the older generation who are slowly dying with this knowledge leading to the loss of valuable information. This is because the knowledge and the methods of processing of the crude drugs are only available in the rural communities and only perpetuated by word of mouth and within families and small communities. Younger people on the other hand who now have taken up formal education rarely get interested in traditional lifestyles. Much of this knowledge therefore is undocumented and in the verge of being lost. Further, the efficacy of majority of the herbal medicines have not been tested to authenticate the traditionally claimed role in disease management.

The common respiratory disease in Kenya is pneumonia which is the inflammation of the respiratory tract involving the lung airways and supporting structures. Pneumonia may be community-acquired (patients are believed to have acquired their infection outside the hospital setting) or hospital acquired (patients are believed to have acquired their infection within the hospital setting). Other priority respiratory infections include tuberculosis, whooping cough and diphtheria. H.I.V infected patients are at high risk of developing pneumonia. Opportunistic infections, (pneumonia being one of them) as a result of severe immunodeficiency, are a major cause of illness and death among such patients. Some of microorganisms responsible for respiratory infections include: Streptococcus pneumoniae, Staphylococcus aureu and Escherichia coli. Respiratory tract infection causing micro-organisms are becoming increasingly resistant to common antibiotics. This has led to the search of novel antimicrobials from plants, which may present a solution to the problem of resistance.

Strptococcus pneumoniae which is estimated to cause $70 \%$ of acute respiratory bacterial infections (Okeke, 2005) is now known to be the leading cause of respiratory tract related deaths globally especially among young children (Malinoski, 2006). This microorganism is a frequent cause of infections in both the community and hospital but has now acquired increasing resistance to various antibiotics worldwide (Werthein et al., 2005). Antimicrobial resistance is a global problem but more pressing in developing countries where infectious disease burden is high and cost constraints restrict the use of newer and more expensive agents (Okeke, 2005). Bacterial antibiotic resistance has now been detected in more than 100 antibiotics and many exhibit resistance to multiple agents (Ott and Morris, 2008). This increase in antibiotic resistance has been attributed to excessive, indiscriminate or inappropriate use of antibiotics in clinical medicine as well as the use of antibiotics as feed additives to promote growth in livestock (Tambe et al., 2001; Swaffham, 2005). A survey by Union of Concerned Scientist reveals for example that $70 \%$ of all antibiotics in the United States are routinely put in the food and water of healthy animals at the cost of about 24 million pounds per year (Rossenblatt-Farrell, 2009).

This study aimed at carrying out an ethnobotanical survey in Kibwezi to document medicinal plants used for respiratory tract infections and test the efficacy of common herbal (aqueous and methanolic) preparations against some microorganisms known to cause respiratory infections.

\section{Materials and Methods Study Area}

Kibwezi $\left(2^{\circ} 25^{\prime} \mathrm{S} 37^{\circ} 58^{\prime} \mathrm{E} 2.42^{\circ} \mathrm{S} 37.97^{\circ} \mathrm{E}\right)$ is situated in Makueni District in the Eastern province of Kenya. The area is occupied by the Akamba people who form the fourth largest tribe in Kenya. Traditionally, the Akamba people were seminomadic and possessed large herds of cattle often practicing limited cultivation. They are well known for their knowledge of medicinal plants and could be one of the groups in Kenya that has best preserved their traditional knowledge on the use of local plants for medicinal purposes.

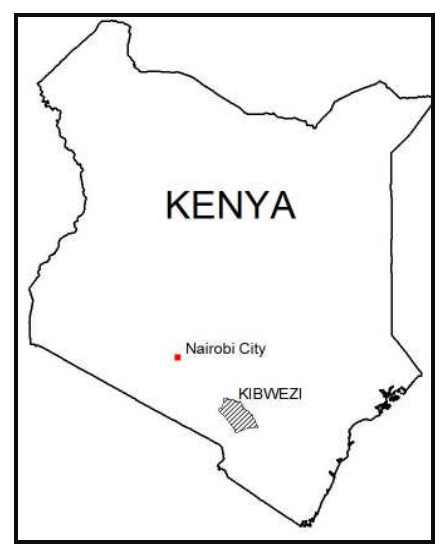

Figure 1: Study area showing location of Kibwezi 
Kariuki and Njoroge Afr J Tradit Complement Altern Med. (2011) 8(2):144-149

\section{Ethnobotanical methodology}

Before undertaking the field work, local community leaders were approached so as to help identify people who were knowledgeable in traditional utilisation of local medicinal plants. Purposeful sampling technique was used as a tool for identifying key informants familiar with the area and uses of plants. These comprised people who were recommended by community leaders as knowledgeable in the use of traditional medicinal plants and hence were incorporated in the study as field guides. Key informants have been used in earlier studies as guides because they are known to be observant and reflective members of the community who know about the culture and are willing to share their knowledge (Garcia, 2006; Tongco, 2007). Oral prior-informed consent was sought before interviews were carried. A descriptive research design was used. An interview guide, consisting of semi-structured questions was used as an instrument for data collection. A pilot test was carried out with a few respondents to pretest the instrument. Any ambiguous questions were edited before starting the interviews and respondents who had participated in the pretesting were eliminated in the study. Information on history of respiratory tract infections, plants used in cases of infection and methods of preparation of the herbal extracts was collected. A total of 30 people were interviewed: these included traditional healers and local people who use traditional plants for self-medication or treating their family members. Information gathered included the species used for managing lower respiratory conditions, parts used as well as methods applied in preparing the crude drugs. Botanical identification was carried out using the relevant taxonomic literature such as local Floras. Herbarium specimens were collected to act as voucher specimens. These are deposited at the Jomo Kenyatta University herbarium as a reference collection.

\section{Plant preparation and extraction}

The plant parts collected from the field were dried at ambient temperature for 48 hours. The plant parts were then macerated and ground, and the powder was collected in a clean jar.

i) Methanolic extraction: Twenty grams of the powder from each plant was subjected to extraction using $250 \mathrm{ml}$ of solvent, methanol. This process was conducted for 9 hours for each plant specimen.

The resultant extract was concentrated by evaporation, where $80 \%$ of the methanol was removed by heating at $40^{\circ} \mathrm{C}$ and vacuum suction.

The extracts were then filter sterilized using microbial membrane filters and poured into sterile labeled bijou bottles.

ii) Water extraction: the ground plant material were boiled in $250 \mathrm{ml}$ of water in a conical flask, for 2 hours. The mixture was then sieved using a tea strainer and the filtrate collected into a beaker. Further filtration was conducted with a filter paper, where the remaining sediments were removed. The final filtrate was filter sterilized and put into sterile labeled bijou bottles.

\section{Reviving of Stock cultures}

Stocks of E. coli, S. aureus and S. pneumoniae were revived in media. E. coli and S. aureus were revived in nutrient broth, while $S$. pneumoniae was revived in 5\% sheep blood agar. All isolates were incubated at $37^{0} \mathrm{C}$ for $24 \mathrm{hrs}$.

- Nutrient Broth:- A liquid basal media that supports growth of nutritionally undemanding micro-organisms. It contains beef extract and peptone in aqueous solution and sodium chloride (each; $0.5 \% \mathrm{w} / \mathrm{v})$.

- Blood agar:- This media is used for culturing fastidious micro-organisms, and for detection of hemolysin. It is prepared by mixing 5-10\% of aseptically drawn blood with pre-autoclaved molten agar base and trypticase soy agar.

\section{Bioassay}

This is a quantitative procedure in which a given organism is used for assay purposes e.g. measuring concentrations of anti microbial agents. A single disk diffusion method was used to assess the presence of antimicrobial activities in water and methanol extracts of the different plants. Whatman's filter paper was punched, and $6 \mathrm{~mm}$ disks collected in a beaker. The beaker was covered with foil paper and autoclaved. The sterile extracts of all plants were serially diluted, using sterile distilled water as a diluent. The disks were dipped into the dilutions and left to air dry on a clean bench. The revived test organisms were plated onto Mueller-Hinton agar plates, but S.pneumoniae was plated on Mueller-Hinton enriched with 5\% sheep blood. The disks were then placed at equidistance on all plates, for all extracts. This was done in triplicates. The plates were incubated at $37^{\circ} \mathrm{C}$ for $24 \mathrm{hrs,}$ after which results were observed and recorded in tables.

\section{Results and discussion}

From the ethbotanical survey it was realized that Acacia nilotica, Strychnos heninningsii and Microglossa densiflora are the most popular plants in management of respiratory tract infections in Kibwezi (Figure 2). 


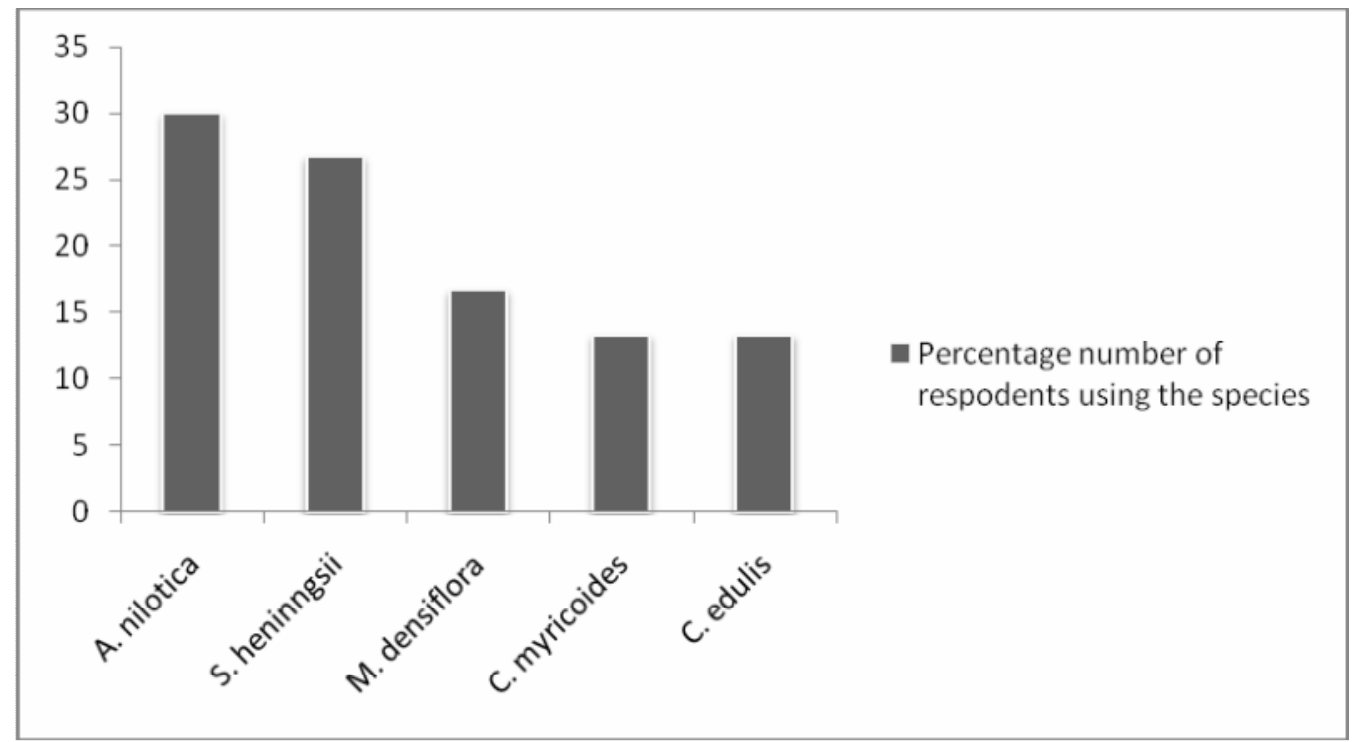

Figure 2: Frequency of use of various plant species in managing respiratory tract infections in Kibwezi.

It is important to note that $A$.nilotica, S. heninngsii and $M$. densiflora are trees while Clerodendrum myericoides and Carrisa edulis are shrubs. All these plants occur in semi-arid areas. In Kenya biodiversity in arid and semiarid areas is under threat due to over-utilization, effects of desertification as well as global warming. In terms of parts utilized in the preparation of these crude drugs most of them are obtained from roots and barks (Figure 3). Considering the majority of the species used are trees, this possesses a major threat to their continued availability as these methods of harvesting are destructive. Methods of raising more populations such as micro-propagation for purposes of sustainable utilization in Kibwezi may be necessary. Local plant users need to be encouraged to conserve these trees by maintaining them on-farm.

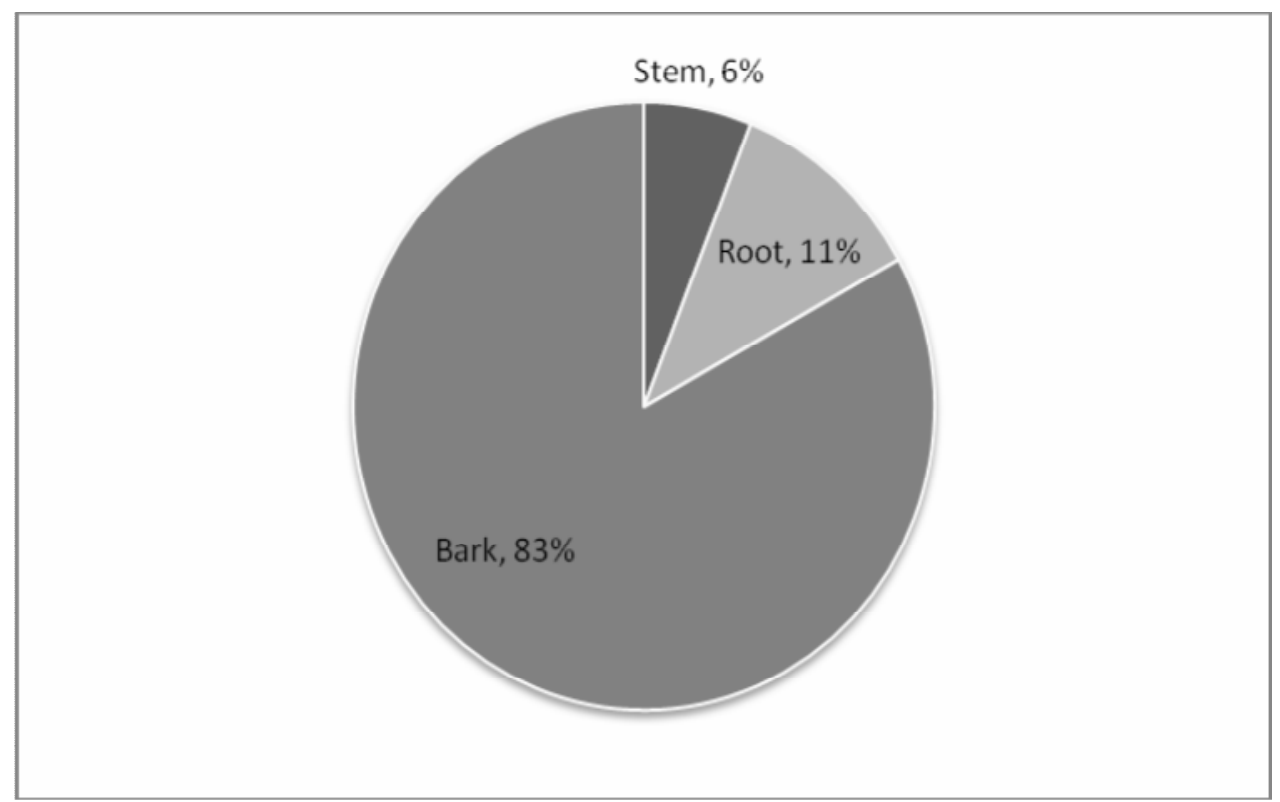

Figure 3: Plant parts utilized in preparation of concoctions for respiratory infections in Kibwezi

None of the tested water extracts of A. nilotica, S. heninngsii and M. densiflora showed any efficacy against $S$. aureus, $S$. pneumoniae or E. coli. It is possible therefore the active ingredients were absent or present in minute quantities and therefore insignificant amounts. It is also possible that the active ingredients were not water-soluble and therefore could not be extracted in an aqueous medium. This is interesting data because in $83 \%$ of the plant species the local herbalists used boiling (in water) as the method of extracting the crude drug for managing respiratory tract infections. In development of herbal medicine industry in 
Kenya, it is important to train traditional healers on other potential extracting media as most of them use water as the main medium.

Methanolic extracts of A. nilotica and S. heninngsii showed efficacy against test organisms S. aureus, S. pneumoniae and E. coli. The methanolic extract of $M$. densiflora however did not show any efficacy. Results on antimicrobial activity trials of the extracts of Acacia nilotica and S. heninngsii against the test organisms, at different concentrations reveal that inhibition zone diameters decrease with decrease in extract concentrations Table 1). This means that the more concentrated the extract, the higher the activity against the organism.

Table 1: Levels of activity of extracts against the test microorganisms

\begin{tabular}{|c|c|c|c|c|c|c|c|c|c|c|c|c|c|c|c|c|c|c|}
\hline \multirow{2}{*}{\multicolumn{2}{|c|}{$\begin{array}{l}\text { Zones of inhibition - E. coli } \\
\text { ilutions of extracts } 10^{\circ}\end{array}$}} & & & & & & \multicolumn{6}{|c|}{ Zones of inhibition- Staphylococcus aureus } & & \multicolumn{5}{|c|}{ Zone of inhibition-S. pneumonie } \\
\hline & & $10^{1}$ & $10^{2}$ & $10^{3}$ & $10^{4}$ & $10^{5}$ & $10^{0}$ & $10^{1}$ & $10^{2}$ & $10^{3}$ & $10^{4}$ & $10^{5}$ & $10^{\circ}$ & $10^{1}$ & $10^{2}$ & $10^{3}$ & $10^{4}$ & $10^{5}$ \\
\hline ilotica & 10.3 & 8.66 & 6.66 & 0 & 0 & 0 & 11.66 & 9.33 & 6.66 & 0 & 0 & 0 & 8.6 & 6.66 & 0 & 0 & 0 & 0 \\
\hline henningsii & 10.3 & 8.33 & 7.33 & 0 & 0 & 0 & 13 & 11.33 & 9.33 & 0 & 0 & 0 & 9 & 7.66 & 0 & 0 & 0 & 0 \\
\hline
\end{tabular}

The minimum inhibitory concentrations for Acacia nilotica were as follows: S.aureus- the lowest dilution that has activity (M.I.C) is $0.8 \mathrm{mg} / \mathrm{ml}$, S. pneumoniae- the lowest dilution that has activity(M.I.C) is $8 \mathrm{mg} / \mathrm{ml}$, E.coli- the lowest dilution that has activity (M.I.C) is $8 \times 10^{-2} \mathrm{mg} / \mathrm{ml}$. On the other hand the minimum inhibitory concentrations for Strychnos heninngsii were as follows: S. aureus- the lowest dilution that has activity (M.I.C) is $0.8 \mathrm{mg} / \mathrm{ml}$ ' S. pneumoniae- the lowest dilution that has activity (M.I.C) is $8 \mathrm{mg} / \mathrm{ml}$, and E coli- the lowest dilution that has activity ( M.I.C) is $8 \times 10^{-2} \mathrm{mg} / \mathrm{ml}$. Methanolic extracts of Strychnos heninngsii were found to be significantly higher than that of Acacia nilotica $(\mathrm{P}<0.005)$ in regard to $S$. aureus and $S$. pneumoniae. Of the microorganisms used in this trial, S. pneumoniae is known to be resistant to common antibiotics. Considering the extracts of A. nilotica and S. heninngsii but more so the latter showed activity, these results therefore point to the fact that these plants hold potential for discovery of antimicrobial agent with success in dealing with the management of pneumonia, which has become a major killer in Kenya among young children and immuno-compromised individuals. These results are especially significant because Strptococcus pneumoniae is now known to be the leading cause of respiratory tract related deaths globally especially among children (Malinoski, 2006). Acute respiratory tract infections are also associated with viral infections (Williams et al., 2006). It is recommended that the plant extracts from this study be subjected to viruses related to respiratory diseases. Further work especially involving invitro trials with mammalian models are recommended.

\section{Conclusion}

Although the water extracts did not show any antimicrobial activity, the methanolic extracts of A. nilotica and $S$. heninngsii showed an inhibitory effect against the three tested micro-organisms $S$. aureus, S. pneumoniae and E. coli. These results act as pointers to authenticity of traditional medicinal knowledge of the local people of Kibwezi.

\section{References}

1. Akerele, O. (1990). Medicinal Plants in Traditional Medicine. In: Farnsworth, N.R. and Wagner, H. (eds.). Economic and Medicinal Plant Research. Vol.4. Plants and Traditional Medicine. Academic Press Ltd., London.

2. Barnes, P.M.; Powell-Grinner, E.; McFann, K.; Nahin, R.L. (2002). Complementary and Alternative medicine use among adults: United States. Seminars in interactive medicine, 54-71.

3. Carlson, T.J.; Iwu, M.M.; King, S.R.; Obialor, C.; Ozioko, A (1997). Medicinal plant research in Nigeria: An approach for compliance with the Convention on Biological Diversity. Diversity 13: 29-33.

4. Chirchir, J., Mungai, G., Kariuki, P. (2006). Indigenous knowledge and conservation of natural resources: resource medicinal plants utilisation in Eastern Africa. Proceedings of national museums of Kenya first scientific conference. $15^{\text {th }}-17^{\text {th }}$ Nov. pp. 106-111.

5. Fabry, W.; Paul, O.K.; Ansorg, R. (1998). Antibacterial activity of East African medicinal plants. J. Ethnopharmacol. 60: $79-84$.

6. Farnsworth, N.R. (1990). The role of ethnopharmacology in drug development. In Chadwick \& Marsh (eds.). Bioactive compounds from plants. John Wiley \& Sons, NY.

7. Fauci, A. (1998). New Reemerging diseases: The importance of biomedical research. Emerging Infectious Diseases. www.cdc.gov/ncidod/EID/vol4no3/fauci

8. Garcia G.S.C: (2006).The mother-child nexus: knowledge and valuation of wild food plants in Wayanad, Westtern Ghats, India. J. Ethnobiology and Ethnomedicine 2:39.

9. Gasengayire, K. (2003). PROTA11: Medicinal plants: Role, Health, Economic and policy Issues, and Scope PP 172183. 
10. Gessler, M. (1995). The Antimalarial potential of medicinal plants traditionally used in Tanzania, and their use in the treatment of malaria by traditional healers. Inaugural dissertation, Baseler-Schnelldruck, Basel.

11. Gilani, H.A. and Rahman, A. (2005). Trends in ethnopharmacology. J. Ethnopharmacol. 100: 43-49.

12. Githae, J.K. (1995). Ethnomedical practice in Kenya: the case of the Karati Rural Service Centre. In Sindiga I., Nyaigotti-Chacha, C and Kanunal. M. P. (eds.) Traditional medicine in Kenya. East African Educational publishers, Nairobi.

13. Inngjerdingen, K., Nergard, C.S. , Diallo, D., Mounkoro, P.P. and Paulsen, B.S. (2004). An ethnopharmacological survey of plants used for wound healing in Dogonland, Mali, West Africa. J. Ethnopharmacol. 92: 233-244.

14. Iwu, M. (1993). Handbook of African Medicinal Plants. CRC Press, Boca Raton, FL.

15. Makunga, N.P.; Ohilander, L.E.; Smith, M. (2008). Current perspective on an emerging formal natural products sector in South Africa. J. Ethnopharmacol. 119 365-375.

16. Malinoski F.J. (2006). Vaccines for otitis media and other pediatric pneumococcal diseases. Drug Discovery Today: Therapeutic Strategies 3 (2):121-127

17. Njoroge G. N. (2006). Baseline survey on taxonomy within traditional systems in Kenya. BOZONET consultant Nairobi, pp. 6-7.

18. Okeke, I.N. (2005). Antimicrobial resistance in developing countries. Part 1: recent trends and current status. The lancet 5:481-493.

19. Okemo. P.O. (1996). Antimicrobial efficacy of selected medicinal plants used by Kenyan Herbal doctors. Ph.D. thesis, Kenyatta University of Nairobi, 173-190.

20. Ott JA and Morris AN. (2008). Homeopathic alternatives to conventional antibiotics. Bios 79:50-55.

21. Rois, J.L. and Recio, M.C. (2005). Medicinal plants and antimicrobial activity. J. Ethnopharmacol. 100: 80-84.

22. Roseenblatt-Farrell, N. (2009). The landscape of Antibiotic Resistance. Environmental Health Perspectives 117:A244A250.

23. Taylor, J.L.S., Rabe, T., McGaw, L.J., Jager, A.K. and van Stande, J. (2001). Towards the scientific validation of traditional medicinal plants. Plant Growth Regulation 34:23-37.

24. Tongco M.D.C. (2007). Purposeful sampling as a tool for informant selection. Ethnobotany Research \& Applications 5:147-158.

25. van Wyk, B. V., Oudtshoorn, B. V. and Gericke, N. (2002). Medicinal plants of South Africa. Briza publications, Pretoria.

26. Wertheim, H.F.L., Melles, D.C., Vos, M.C., van Leeuwen, W., van Belkum, A., Verbrugh, H.A. and Nouwen, J.L (2005). The role of nasal carriage in Staphylococcus aureus infections. Lancet infectious diseases 5: 751-762.

27. Williams, J.V., Tollefson, S.J., Nair, S. and Chonmaitree, T. (2006). Association of human metapneumovirus with acute otitis media. International J Paediatric Otorhinolaryngology 70: 1189-1193.

28. WHO (2002). World Health Organization fact sheet no. 271. World Health Organization, Geneva. 